
\title{
$\angle$ Research Square \\ COVID-19 and lockdown in India: Evaluation using analysis of covariance
}

\section{Amit Tak ( $\square$ dramittak@gmail.com )}

ICMR- National Institute of Disease Informatics and Research, Bengaluru, Karnataka, India https://orcid.org/0000-0003-2509-2311

\section{Bhaskar Das}

Command Hospital Air Force, Bangalore, Karnataka, India

\section{Saurabh Gahlot}

Vivekananda Institute of Technology (East) Jaipur, Rajasthan, India

\section{Research Article}

Keywords: analysis of covariance, coefficients of regression, COVID-19, lockdown, pandemic

Posted Date: December 30th, 2020

DOl: https://doi.org/10.21203/rs.3.rs-136260/v1

License: (c) (1) This work is licensed under a Creative Commons Attribution 4.0 International License. Read Full License 


\section{Abstract}

Background: The lockdown in India has entered into its ninth month to curb the Coronavirus disease-19 (COVID-19) pandemic. The objective of the present study is to evaluate impact of different phases of lockdown on evolution of new cases of infection and deaths due to COVID-19.

Methods: In this retrospective longitudinal study, the Indian data on new cases of infection and deaths due to COVID-19 were retrieved from John Hopkins University dashboard. The cases from 25 March to 31 October 2020 were analyzed using analysis of covariance for four phases of lockdown and five phases of unlockdown.

Results: The coefficients of regression for new cases did not differ significantly for initial four phases of lockdown and unlock-1, while from unlock-2 the coefficients showed significant decrease till unlock-5. While death cases showed no significant differences between coefficients of regression for initial four phases of lockdown and unlock, but coefficient of unlock-5 was significantly lower than unlock-4.

Conclusion: The trends of coefficients of regression of new cases and deaths reveals positive effects of lockdown in flattening the epidemic curve. Though the pandemic is on downslope, till the availability of vaccine, non-pharmaceutical measures such as social distancing, wearing of mask need to be implemented.

\section{Highlights}

- Strategies during various phases of lockdown policy in India

- Impacts of lockdown in containment of COVID-19 pandemic in India.

- Analyze the evolution of new cases of infection and deaths due to COVID-19 using analysis of covariance.

- Mathematical models that forecast and analyze the impacts of lockdown were discussed

- Role of non-pharmaceutical measures such as social distancing, wearing of mask, sanitization of hands, testing capacity on epidemic curve.

\section{Introduction}

The global visibility of Coronavirus disease-19 deaths propelled Governments worldwide to impose lockdown. In developed nations, the cost of achieving this move is "merely" a substantial economic slowdown. But for India, a developing democracy with a mammoth population of 1.3 billion and vulnerable economy, cost of lockdown is more than economic recession. The lost of lives through violence, starvation, indebtedness and severe stress are invisible. [1] According to the World Health Organization report on 28 November 2020, there have been 61,299,371 confirmed cases of COVID-19, including 1,439,784 deaths globally. [2] As per Ministry of Health and Family Welfare, Government of India there are 453956,8802267 and 136696 active, recovered and death cases respectively in the 
country. [3] India has to face multiple challenges on the COVID-19 front. Physical distancing without total lockdown is unthinkable, especially in big and crowded cities. As per National sample survey reports, only $36 \%$ of Indians wash their hands with soap before meals. Furthermore, 160 millions do not have access to clean water to wash hands. [4] To combat such scenarios and for optimum allocation of resources a number of mathematical models were suggested to forecast evolution of COVID-19 cases, mortality and length of hospital stays. [5] [6] [7] [8] In addition to provision of health services, coordination between various agencies including transport departments, police, food supply departments play a key role. [9].

The objective of the present study was to evaluate the effects of various phases of lockdown on the ongoing COVID-19 transmission and mortality in India.

\section{Material And Methods}

In this retrospective longitudinal study, the evolution of new cases and deaths per day of COVID-19 for Indian subcontinent during various phases of lockdown (25 March to 31 October 2020) were analyzed using analysis of covariance (ANCOVA). The various phases of lockdown include lockdown-1 (LD1), lockdown-2 (LD2), lockdown-3 (LD3), lockdown-4 (LD4), unlock-1 (ULD1), unlock-2 (ULD2), unlock-3 (ULD3), unlock-4 (ULD4) and unlock-5 (ULD5). (Table 1)

\section{Data acquisition:}

The Indian data of new cases of infection and deaths due to COVID-19 from 25 March 2020 to 31 October 2020 ( $N=221$ ) were obtained from the official website of John Hopkins University Center for Systems Science and Engineering (https://systems.jhu.edu/) and the repository

(https://github.com/CSSEGISandData/COVID-19). [10] The time series of new cases, deaths and lockdown phases was build in MS Excel 2010. The LD1 was implemented on 25 March 2020 followed by other phases of lockdown (Table 1).

\section{Data analysis:}

Nine linear regression models were fitted for nine phases of lockdown, where time series data of new cases was taken as dependent variable and time as regressor. Similarly, nine linear regression models were fitted for deaths. The linear regression model can be defined as follows:

$$
y_{i}=a_{i}+b_{i} t+e
$$

where, $a_{i}$ is the intercept and $b_{i}$ is the coefficient of regression and $\mathrm{e}$ is the error term of the models. The coefficient of regression reflects the evolution of new cases or deaths of COVID-19. The higher the value of coefficient of regression means the higher the rate of evolution. The coefficients of regression of various phases of lockdown were compared. 
To compare the coefficients of regression of various phases of lockdown, analysis of covariance (ANCOVA) was performed. The ANCOVA evaluates whether the means of regression coefficient are equal across the various phases of lockdown. The statistical level of significance was considered at $5 \%$. Microsoft Excel 2010 was used for creating database and analysis was performed on MATLAB 2016a $(9.0 .0 .341360)[11]$

\section{Results}

\section{Evolution of new cases of COVID-19}

The plot of new cases per day of COVID-19 showed biphasic trend (Figure 1(a)).The nine linear regression models for new cases of COVID-19 were fitted for nine different phases of lockdown (Figure 2). The mean of the coefficients of regression increases from LD1 to ULD2, then it shows decreasing trends till ULD5 (Table 2). The comparison of coefficients of regression of different phases of lockdown was performed with analysis of covariance $[F(8,203)=1450.03 ; p<0.001]$. The significant differences between various coefficients of regression of new cases can be interpreted from plots of confidence intervals (Figure 3 ). The overlapping between limits of confidence intervals suggests no significant difference exists. We observed that the evolution of new cases of COVID-19 was the highest during ULD2 phase $(b=1246 ; p<$ $0.001)$. Gradually the evolution rate slows in ULD3 $(b=712 ; p<0.001)$ and becomes negative in ULD4 ( $b$ $=163 ; p<0.001)$ and ULD5 $(b=1212 ; p<0.001)$ phases. There were no significant differences between the coefficients of regression of LD1, LD2, LD3, LD4 and ULD1, while ULD2, ULD3, ULD4 and ULD5 differs significantly from each other.

\section{Evolution of death cases}

Similarly, the plot of death cases per day of COVID-19 showed biphasic trend (Figure 1(b)). The nine linear regression models for death cases of COVID-19 were fitted for nine different phases of lockdown (Figure 4). The mean of the coefficients of regression increases from LD1 to ULD2 with mid non-significant fluctuations, then it shows decreasing trends till ULD5 (Table 2). The comparison of coefficients of regression of different phases of lockdown was performed with analysis of covariance $[F(8,203)=197.5$; $p<0.001]$. The significant differences between various coefficients of regression of death cases can be interpreted from plots of confidence intervals (Figure 5 ). We observed that the evolution of new cases of COVID-19 was the highest during ULD2 phase $(b=13.15 ; p<0.001)$. Gradually the evolution rate slows in ULD3 $(b=4.08 ; p=0.48)$ and becomes negative in ULD4 $(b=0.26 ; p=0.46)$ and ULD5 $(b=18.99 ; p<$ $0.001)$ phases. There were no significant differences between coefficients of regression of LD1, LD2, LD3, LD4, ULD1, ULD2, ULD3 and ULD4, but ULD5 differs significantly from ULD4.

\section{Discussion}


On 24 March 2020, a mammoth population of 1.3 billion was restricted to home with announcement of nationwide lockdown by the prime minister of India. The lockdown was aimed to break the chain of transmission and flatten the epidemic curve to curb COVID-19 pandemic. There was suspension of all means of transportation including air, rail and road with the exception of essential services. The educational institutions, industrial establishments, hospitality services were locked. Essential services including food shops, hospitals, medical stores, ATMs, petrol pumps, fire, police were exempted.[12] Subsequently various impositions were partially removed from LD2 and unlock phases has been continuing till now. India consists of 28 heterogeneous states with corresponding dynamics of the COVID-19. [13]

As compared with pre-lockdown period, the doubling rate of new cases was increased from three to eight days during the LD1.[12] The results showed that the rate of evolution of new cases did not differ significantly during the next four phases of lockdown. Singh BP et al. model effects of lockdown on the tempo of COVID-19 and found no significant differences between pre-lockdown rates and LD1 growth rates, but growth rates in LD1 and LD2 differ significantly.[14] Kumar D et al. showed as compared to prelockdown and LD1, the doubling time in LD2 was higher. On 14 April 2020, with the end of LD1, the LD2 was announced till 3 May 2020.[15] On 20 April 2020, government allowed some relaxations that include, opening of agricultural businesses such as dairy, aquaculture, plantations and shops selling farm products with proper maintenance of social distancing. Further, the cargo transportation vehicles were allowed.[12] The demographic profile of initial 2500 COVID-19 sufferers revealed $59 \%$ belongs to age group of 20 - 49 years, that constitute the working age group.[16]

As on 4 May 2020, LD3 had been continued with some more relaxations as announced by the Ministry of Home Affairs, Government of India. Based on doubling rates, the lockdown areas in the whole country were divided into 'red zone', 'orange zone', and 'green zone' with high, moderate and low doubling rates respectively. In red zones, no movement of public was permitted, while in orange zones, private and hired vehicles are permitted. In green zones, buses with $50 \%$ carrying capacity were allowed.[12] Sahoo BK et al. suggested mathematical model, where time dependent infection rate (depend on lockdown) was fitted with Gompertz function and effects of lockdown were modeled. The initial infection rate was 0.15 per day which has come down to about 0.05 per day (about 3 times lower) after 6 weeks of lock down and the downward trend continues, as suggested in the present study.[17] Pai C used SEIR Model (susceptibleexposed-infected-recovered model) to predict the impact of removal of lockdown on $3^{\text {rd }}$ May 2020 . They predicted that peak of active infected cases would be around 43,000 in the mid of May, 2020 with 7 to $21 \%$ increase in peak value due to relaxation in lockdown strategies. [18] From 18 May 2020, LD4 continued and more power were given to states to demarcate zones. The average daily number of tests have increased from 1,717 (19-25 March) to 131,772 (25-31 May) with an estimated testing shortfall of 4.58 million tests nationally by 31 May 2020.[19]

In view of economical impacts of lockdown, relaxations in ULD1 allowed shopping malls, religious places, hotels and restaurants to reopen. Still no inter-state travel was allowed and night curfew continued. Further as part of ULD2, a number of activities were allowed outside of containment zones, the 
only exception were educational institutions, international air travel, places of recreation such as swimming pools, gymnasiums, theatres, entertainment parks, bars, auditoriums and assembly halls. The inter-state borders were open. From ULD1 to ULD2 the rate of evolution increases, but after ULD2, rate of evolution has been decreasing. Since ULD3, night curfews were removed and gymnasiums and yoga centers were allowed to open. With LD4, marriages and funerals ceremonies were allowed and religious, political, sports and academic gathering up to 100 persons were allowed.[12] Vaishnav $V$ et al. used group method of data handling to assess the impact of relaxations during lockdown. They reported that apart from relaxations in LD3 and LD4, the increased testing capacity and migration of laborers were important reasons of increased positive cases.[20] During LD5, major relaxations include opening of cinema halls with $50 \%$ sitting capacity and reopening of hill stations, beaches and national parks. The results showed that the evolution of death cases due to COVID-19 closely parallels the evolution of new cases of infection .(Figure 3 and 5).

However, Mate A et al used SEIR model to compare range of policies. After the initial lockdown, their simulations demonstrate that even policies that enforce strict physical distancing while returning to normal activity could lead to widespread outbreaks. However, "middle ground" policies that alternate weekly between total lockdown and physical distancing may lead to much lower rates of infection while simultaneously permitting some return to normalcy. [21] Nadim S et al. performed the dynamical analysis of the impact of lockdown on disease transmission. The impact of lockdown of susceptible individuals will have always positive population-level impact for every $0<r<1$, where $r$ is lockdown efficacy. The lockdown of susceptible individuals resulted in reduction of the basic reproduction number. [22] Finally, India was quick to implement lockdown and closing its international borders as praised by World Health Organisation as "tough and timely". [23]

\section{Conclusion}

The timely lockdown in India has a key role in curbing the COVID-19 pandemic. Furthermore, the partial relaxations during ongoing pandemic are appropriate measures to deal with medical as well as economical issues of the country. Now the pandemic is on its downslope, but till the availability of vaccine, non-pharmaceutical measures such as social distancing, wearing of mask and sanitization of hands need to be implemented.

\section{Limitations Of The Study}

The small number of time points for initial phases of lockdown, that is, LD1, LD2, LD3 and LD4 contains $21,19,14,14$ days respectively.

\section{Declarations}

Contribution of Authors: AT did concept design, analysis and interpretation, BD helps in manuscript writing and literature review, SG helped in collection and assembly of data and literature review. All 
authors commented and finally approved the manuscript.

Competing Interest: The authors declare that they have no known competing financial interests or personal relationships that could have appeared to influence the work reported in this paper.

Data Availability - Data is available on reasonable request from corresponding author.

Ethics Declarations: The present study used de-identified data from public domain, thus exempted from ethical review by Institutional Ethics Committee.

\section{References}

1. Ray D, Subramanian S. India's Lockdown: An Interim Report. National Bureau of Economic Research; 2020 May 28. Available from: DOI3386/w27282

2. World Health Organizaton, WHO Coronavirus Disease (COVID-19) Dashboard [Accessed on: 28 November 2020] Available from : https://covid19.who.int/

3. Ministry of Health and Family Welfare, Government of India. [Internet] Accessed on : 29 Nov 2020. Available at : https://www.mohfw.gov.in/

4. Kamath S, Kamath R, Salins P. COVID-19 pandemic in India: challenges and silver linings. Postgraduate medical journal. 2020 Jul 1;96(1137):422-3. Available from: http://dx.doi.org/10.1136/postgradmedj-2020-137780

5. Bhandari S, Tak A, Singhal S, Shukla J, Patel B, Shaktawat AS, et al. Patient flow dynamics in hospital systems during times of COVID-19: Cox proportional hazard regression analysis. [Internet]. Frontiers in Public Health; 2020. Available from: doi: 10.3389/fpubh.2020.585850

6. Chatterjee K, Shankar S, Chatterjee K, Yadav AK. Coronavirus disease 2019 in India: Post-lockdown scenarios and provisioning for health care. Medical Journal Armed Forces India. 2020 Oct 1;76(4):387-94. Available from : https://doi.org/10.1016/j.mjafi.2020.06.004

7. Bhandari S, Shaktawat AS, Tak A, Patel B, Shukla J, Singhal S, Gupta K, Gupta J, Kakkar S, Dube A. Logistic regression analysis to predict mortality risk in COVID-19 patients from routine hematologic parameters. Ibnosina J Med Biomed Sci [serial online] 2020 [cited 2020 Jun 30];12:123-9. Available from: http://www.ijmbs.org/text.asp?2020/12/2/123/288204

8. Bhandari S, Tak A, Gupta J, Patel B, Shukla J, Shaktawat AS, et al. Evolving trajectories of COVID-19 curves in India: Prediction using autoregressive integrated moving average modeling. [Internet]. Research Square; 2020. Available from: http://dx.doi.org/10.21203/rs.3.rs-40385/v1

9. Dore B. Covid-19: collateral damage of lockdown in India. BMJ. 2020 Apr 30;369. https://doi.org/10.1136/bmj.m1711 
10. Johns Hopkins University Center for Systems Science and Engineering, 2019. (Accessed : 15 Nov 2020). Available from: https://github.com/CSSEGISandData/COVID-19

11. MATLAB Team. Statistics Machine Learning Toolbox 10.2. MATLAB. version 9.0.0.341360 (R 2016a). Natick, MA: The Mathworks Inc. 2016

12. Wikipedia COVID-19 pandemic lockdown in India. [Internet] Accessed on: 29 November 2020 Available at: https://en.wikipedia.org/wiki/COVID-19_pandemic_lockdown_in_India

13. Bhandari S, Shaktawat AS, Tak A, Patel B, Gupta K, Gupta J, Kakkar S, Dube A. A multistate ecological study comparing evolution of cumulative cases (trends) in top eight COVID-19 hit Indian states with regression modeling. Int J Acad Med [serial online] 2020 [cited 2020 Jun 30];6:91-5. Available from:http://www.ijam-web.org/text.asp?2020/6/2/91/287965

14. Singh, B. P., \& Singh, G. (2020). Modeling tempo of COVID-19 pandemic in India and significance of lockdown. Journal of public affairs, e2257. Advance online publication. Available from: https://doi.org/10.1002/pa.2257

15. Kumar, D., Raina, S. K., Chauhan, R., Kumar, P., \& Sharma, S. (2020). Drawing inference from nationwide lockdown as a response towards novel Cornavirus-19 (CoVID-19) epidemic in India. Journal of family medicine and primary care, 9(9), 4507-4511.Available from: https://doi.org/10.4103/jfmpc.jfmpc_807_20

16. Mahajan P, Kaushal J. Epidemic Trend of COVID-19 Transmission in India During Lockdown-1 Phase. J Community Health [Internet]. 2020 Jun 23:45(6):1291-300. Available from : https://doi.org/10.1007/s10900-020-00863-3

17. Sahoo BK, Sapra BK. A data driven epidemic model to analyse the lockdown effect and predict the course of COVID-19 progress in India. Chaos, Solitons \& Fractals. 2020 Oct 1;139:110034. https://doi.org/10.1016/j.chaos.2020.110154

18. Pai, C., Bhaskar, A., \& Rawoot, V. (2020). Investigating the dynamics of COVID-19 pandemic in India under lockdown. Chaos, solitons, and fractals, 138, 109988. Available from: https://doi.org/10.1016/j.chaos.2020.109988

19. Basu, D., Salvatore, M., Ray, D., Kleinsasser, M., Purkayastha, S., Bhattacharyya, R., \& Mukherjee, B. (2020). A Comprehensive Public Health Evaluation of Lockdown as a Non-pharmaceutical Intervention on COVID-19 Spread in India: National Trends Masking State Level Variations. med;Rxiv : the preprint server for health sciences, 2020.05.25.20113043. Available from : https://doi.org/10.1101/2020.05.25.20113043

20. Vaishnav, V., \& Vajpai, J. (2020). Assessment of impact of relaxation in lockdown and forecast of preparation for combating COVID-19 pandemic in India using Group Method of Data 
Handling. Chaos, solitons, and fractals, 140, 110191. Available from:

https://doi.org/10.1016/j.chaos.2020.110191

21. Mate A, Killian JA, Wilder B, Charpignon M, Awasthi A, Tambe M, Majumder MS. Evaluating COVID-19 Lockdown Policies For India: A Preliminary Modeling Assessment for Individual States., in SSRN. ; 2020. Available from: http://doi.org/10.2139/ssrn.3575207

22. Nadim, S. S., \& Chattopadhyay, J. (2020). Occurrence of backward bifurcation and prediction of disease transmission with imperfect lockdown: A case study on COVID-19. Chaos, solitons, and fractals, 140, 110163. Available from: https://doi.org/10.1016/j.chaos.2020.110163.

23. Lancet T. India under COVID-19 lockdown. Lancet (London, England). 2020 Apr 25;395(10233):1315. https://dx.doi.org/10.1016\%2FS0140-6736(20)30938-7

\section{Tables}

Table 1. shows duration of various phases of lockdown and number of time points taken for analysis. [12]

\begin{tabular}{ccc}
\hline Phases of lockdown & Time period & Duration (days) \\
\hline Lockdown 1 & 25 March 2020 - 14 April 2020 & 21 \\
Lockdown 2 & 15 April 2020 - 3 May 2020 & 19 \\
Lockdown 3 & 4 May 2020 - 17 May 2020 & 14 \\
Lockdown 4 & 18 May 2020 - 31 May 2020 & 14 \\
Unlock 1 & 1 June 2020 - 30 June 2020 & 30 \\
Unlock 2 & 1 July 2020 - 31 July 2020 & 31 \\
Unlock 3 & 1 August - 31 August 2020 & 31 \\
Unlock 4 & 1 September 2020 - 30 September 2020 & 30 \\
Unlock 5 & 1 October 2020 - 30 October 2020 & 31 \\
\hline
\end{tabular}

Table 2. showing estimates of coefficients of regression of new cases of infection and deaths due to COVID-19 in various phases of lockdown and unlock in India

\begin{tabular}{ccccc}
\hline Phases of lockdown & \multicolumn{2}{c}{ New COVID-19 cases } & New deaths due to COVID-19 \\
\cline { 2 - 5 } & Estimate & $p$ & Estimate & $p$ \\
\hline Lockdown 1 & 55 & 0.453 & 2.03 & 0.994 \\
Lockdown 2 & 79 & 0.612 & 3.13 & 0.829 \\
Lockdown 3 & 97 & 0.794 & -0.27 & 0.778 \\
Lockdown 4 & 241 & 0.745 & 7.89 & 0.463 \\
Unlock 1 & 395 & 0.013 & 7.23 & 0.087 \\
Unlock 2 & 1246 & $<0.001$ & 13.15 & $<0.001$ \\
Unlock 3 & 712 & $<0.001$ & 4.08 & 0.481 \\
Unlock 4 & -163 & 0.0006 & -0.26 & 0.459 \\
Unlock 5 & -1212 & $<0.001$ & -18.99 & $<0.001$ \\
\hline
\end{tabular}


Figures
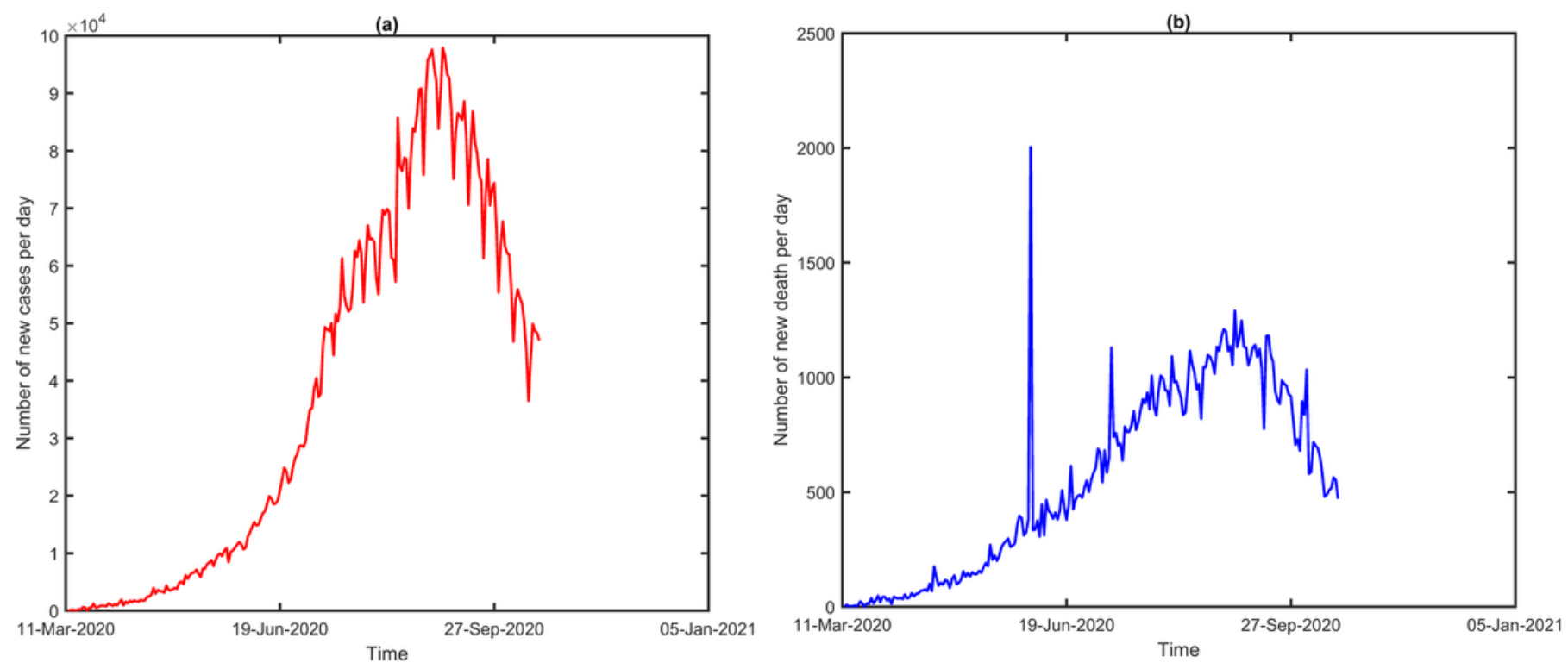

Figure 1

Line plots show the evolution of new cases and deaths per day due to COVID-19 in India. (a) New cases of COVID-19 per day (b) Deaths due to COVID-19 per day
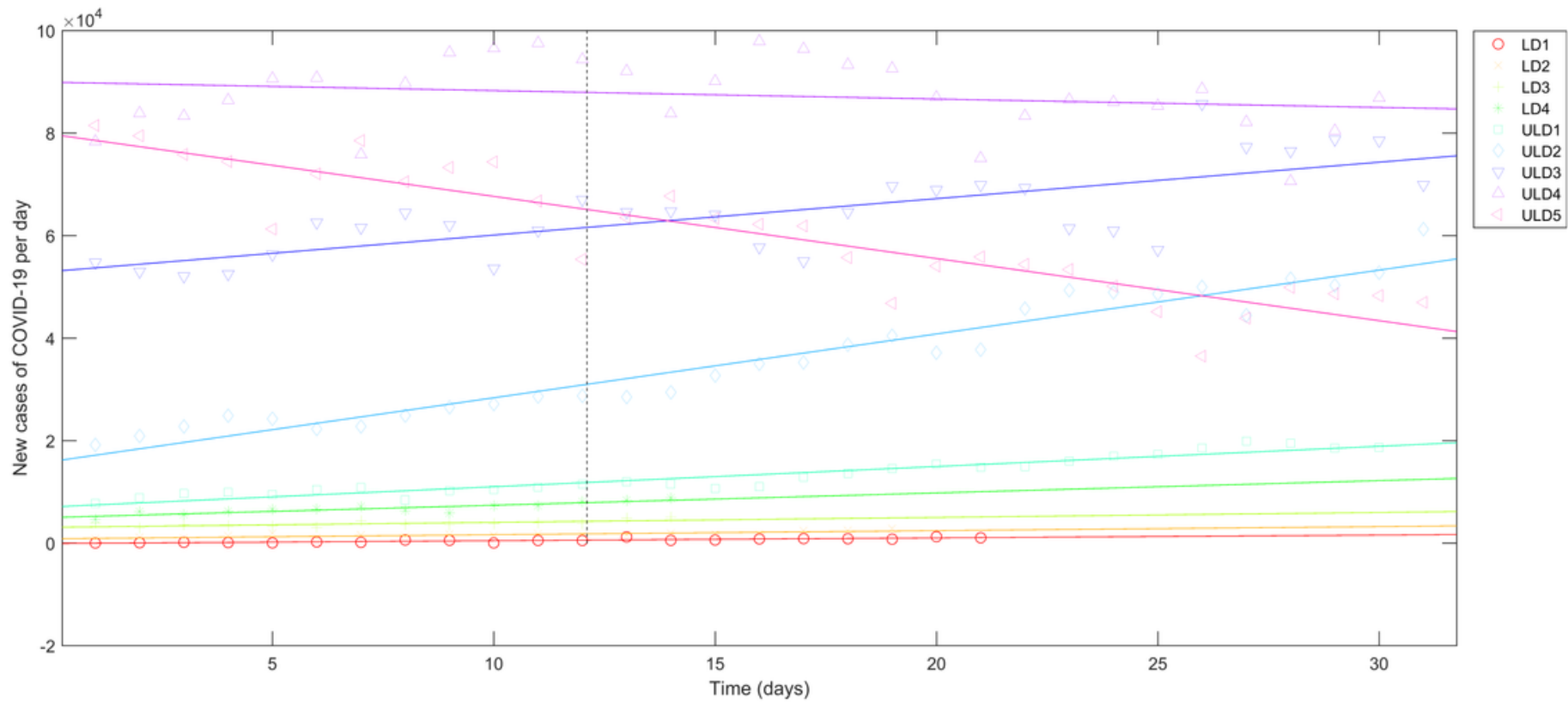

Figure 2 
Shows nine linear regression models for various phases of lockdown with dependent variable as new cases of COVID-19 and time as regressor.

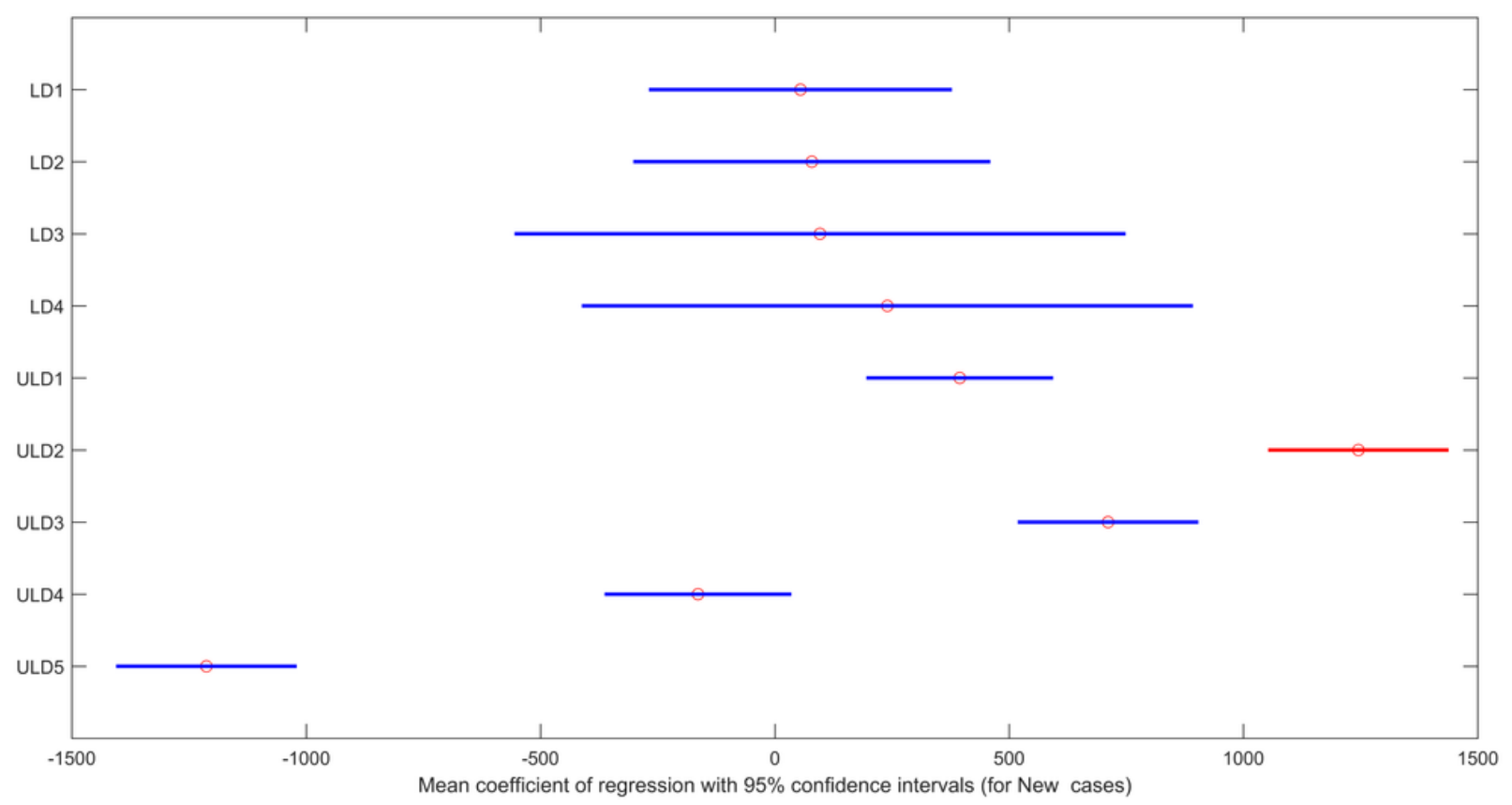

\section{Figure 3}

Shows coefficients of regression with $95 \%$ confidence interval of linear regression models of new cases of COVID-19 for nine phases of lockdown.

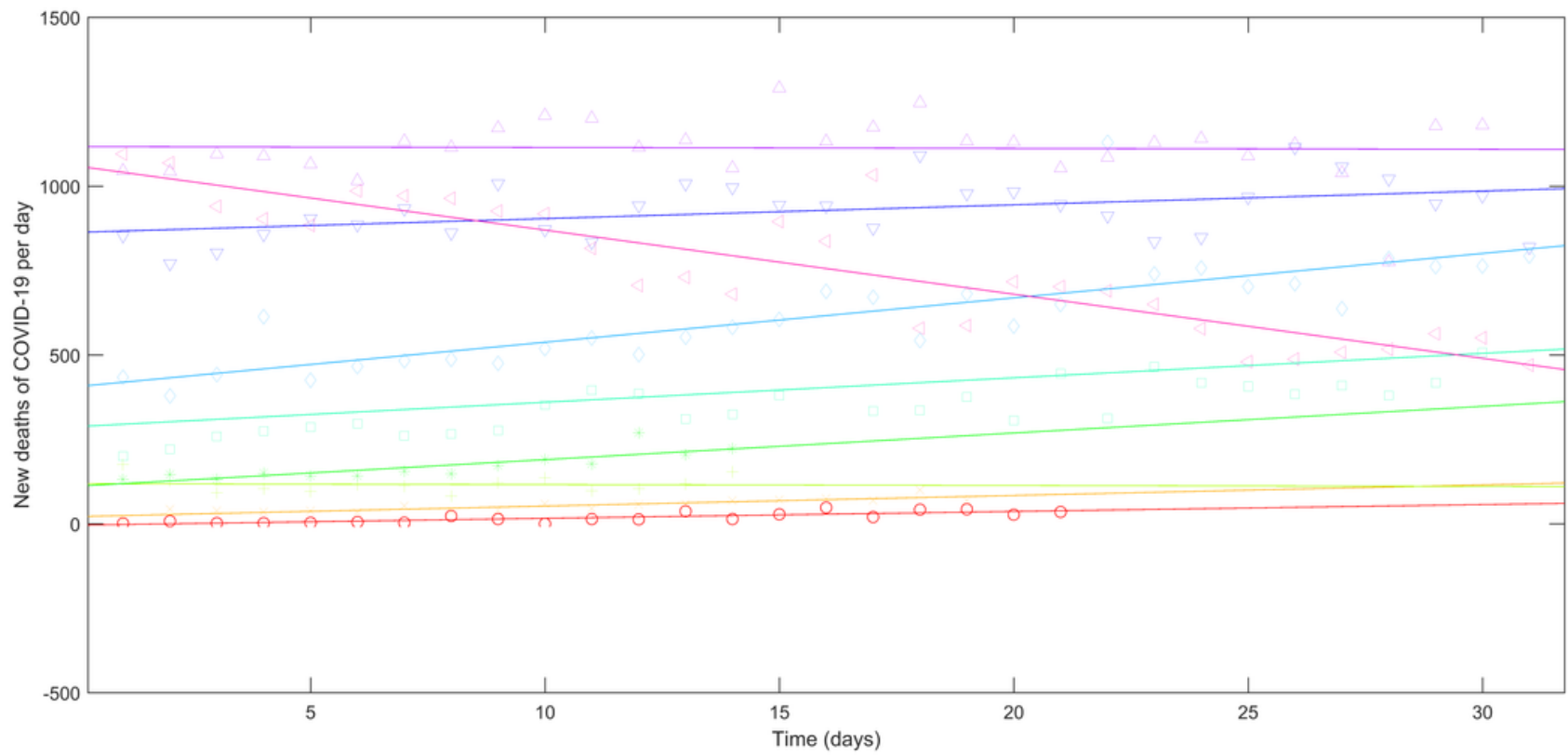

Figure 4 
Shows nine linear regression models for various phases of lockdown with dependent variable as new death cases due to COVID-19 and time as regressor.

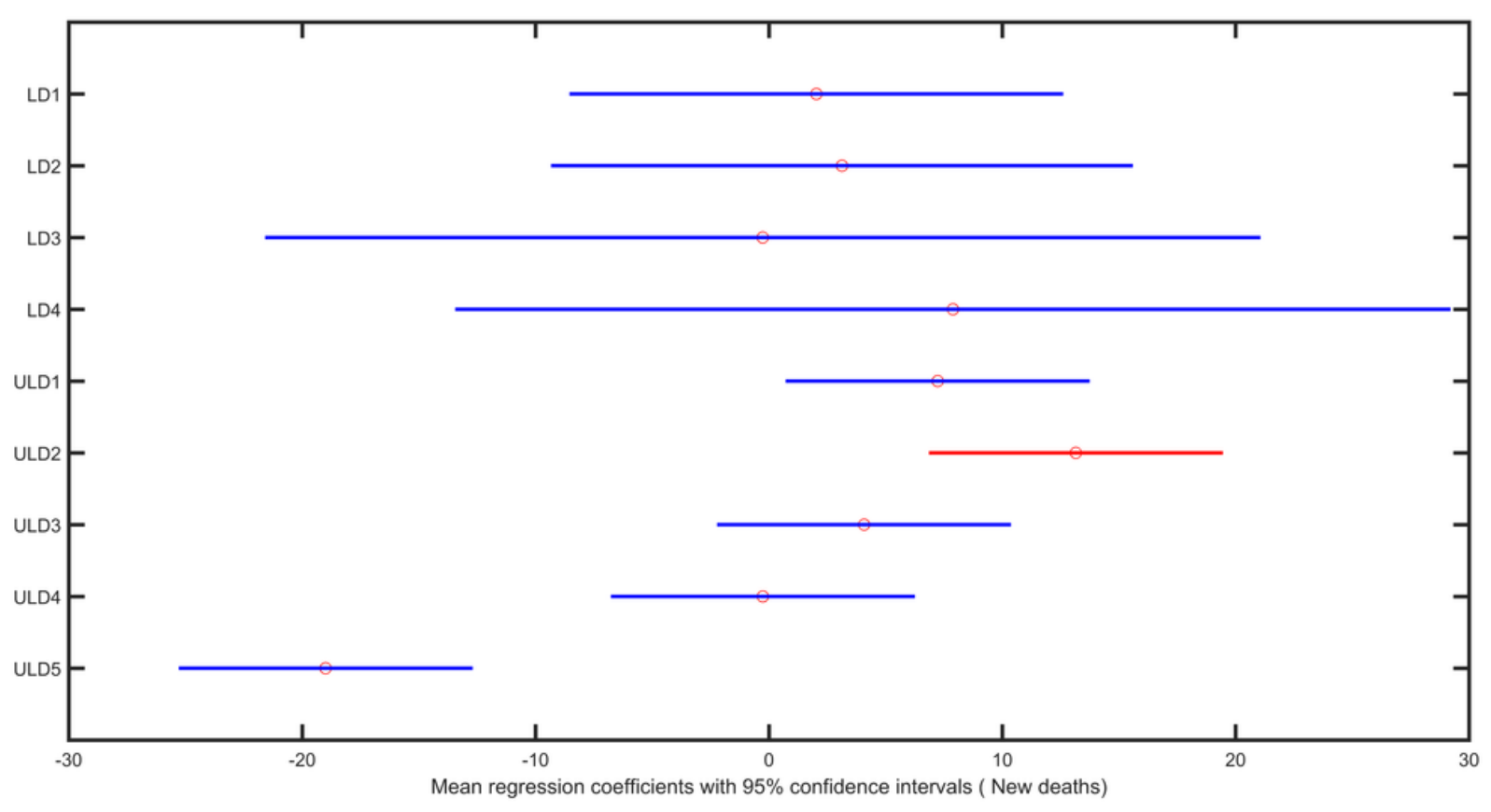

\section{Figure 5}

Shows coefficients of regression with $95 \%$ confidence interval of linear regression models of new deaths cases due to COVID-19 for nine phases of lockdown. 